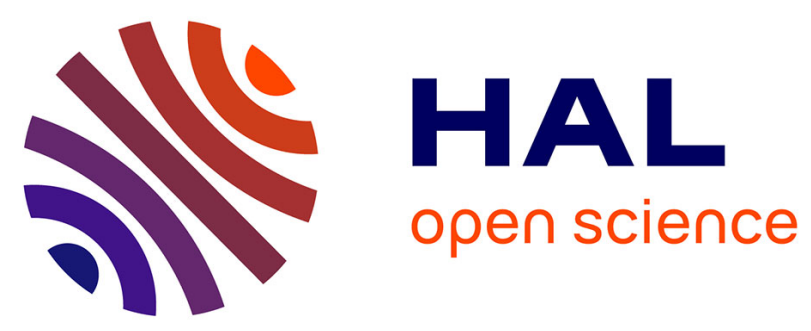

\title{
Apparent Electrical Conductivity as a Tool for Earthworm Parameters Evaluation in a Commercial Orchard
}

\author{
E. Lardo, A. M. Palese, Aissa Arous, G. Ferrazzano, C. Xiloyannis, G. Celano, \\ Patrice Coll, Edith Le Cadre, Eric Blanchart, Cecile Villenave
}

\section{To cite this version:}

E. Lardo, A. M. Palese, Aissa Arous, G. Ferrazzano, C. Xiloyannis, et al.. Apparent Electrical Conductivity as a Tool for Earthworm Parameters Evaluation in a Commercial Orchard. 8. International Peach Symposium, International Society for Horticultural Science (ISHS). INT., Jun 2013, Matera, Italy. 10.17660/ActaHortic.2015.1084.66 . hal-02741321

\section{HAL Id: hal-02741321 \\ https://hal.inrae.fr/hal-02741321}

Submitted on 3 Jun 2020

HAL is a multi-disciplinary open access archive for the deposit and dissemination of scientific research documents, whether they are published or not. The documents may come from teaching and research institutions in France or abroad, or from public or private research centers.
L'archive ouverte pluridisciplinaire HAL, est destinée au dépôt et à la diffusion de documents scientifiques de niveau recherche, publiés ou non, émanant des établissements d'enseignement et de recherche français ou étrangers, des laboratoires publics ou privés. 


\section{"Apparent electrical conductivity as a tool for earthworm parameters evaluation in a commercial orchard"}

Egidio LARDO ${ }^{1}$, Patrice COLL $^{2}$, Assunta Maria PALESE ${ }^{*}$, Aissa AROUS ${ }^{1}$, Giuseppe FERRAZZANO ${ }^{1}$, Edith LE CADRE ${ }^{2}$, Cécile VILLENAVE ${ }^{3-4}$, Eric BLANCHART ${ }^{2}$, Cristos XILOYANNIS $^{1}$, Giuseppe CELANO ${ }^{1}$

${ }^{1}$ Department of European and Mediterranean Cultures, Environment and Cultural Heritage,

University of Basilicata, via A. di Francia, 75100 MATERA, Italy;

${ }^{2}$ SupAgro Montpellier, UMR Eco\&Sols (SupAgro, CIRAD, INRA, IRD), 2 place Viala, 34060 MONTPELLIER France; ${ }^{3} I R D$, UMR Eco\&Sols (SupAgro, CIRAD, INRA, IRD), 2 place Viala, 34060 MONTPELLIER, France; ${ }^{4}$ ELISOL environnement, 2 place Viala, 34060 MONTPELLIER, France;

*corresponding author: assunta.palese@unibas.it

\section{Introduction}

The non-invasive geophysical techniques, such as EMI (Electromagnetic Induction), are innovative approaches to study soil biological parameters.

\section{Objectives}

This work was carried out to assess relationships between soil earthworm abundance and biomass and soil apparent electrical conductivity $\left(\mathrm{EC}_{\mathrm{a}}\right)$ measured by means of a GSSI EMP-400 Profiler.

\section{Research Scenario and Measurements}

Soil:

Soil management:

Geophysical

measurements:
Peach orchard:

cv Springbrigth/GF677 rootstock transversal Y (1111 plants ha-1)

Clay loam classified as Vertic Calcixerepts (SSS, 1998)

Chemical Weeded on tree rows-CW

Cover Cropped between tree rows-CC

Soil EMI (ElectroMagnetism Induced) performed by a multifrequency EMP-400 Profiler (GSSI, Salem, NH-USA)

Earthworms evaluation was performed by sampling twenty areas $\left(\begin{array}{lllll}1 & \mathrm{~m} & \mathrm{x} & 1 & \mathrm{~m}\end{array}\right)$ according to a regular grid pattern (20 areas/ha) (Photo 1).

Earthworm sampling was carried out by means of the mustard method combined with hand-sorting (Pelosi et al., 2009). Measurements of endogeic and anecic earthworm abundances (ind $/ \mathrm{m}^{2}$ ) and biomasses $\left(\mathrm{g} / \mathrm{m}^{2}\right)$ were then performed in the laboratory.

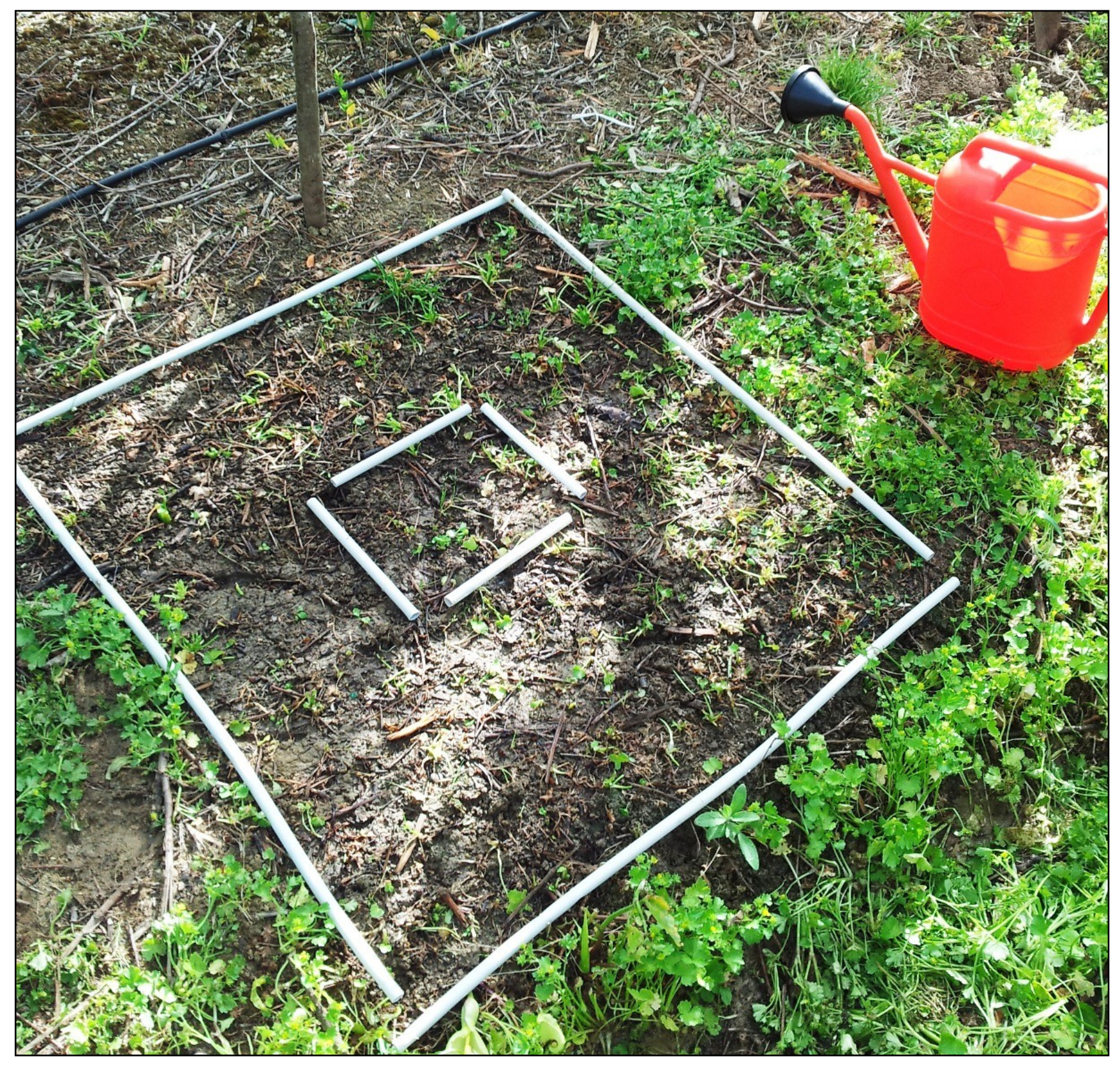

Photo 1. Single area for earthworms sampling

\section{Results and Discussion}

$\mathrm{EC}_{\mathrm{a}}$ values rose as the used wavelengths decreased and soil depth exploration increased. Soil $\mathrm{EC}_{\mathrm{a}}$ map, performed at $3 \mathrm{kHz}$ frequency, is reported in Fig. 1. As found by Joschko et al. (2010) in cereal field, by Valckx et al. (2009) in horticultural arable fields and by Lardo et al. (2012) for tilled and cover cropped vineyards, the $\mathrm{EC}_{\mathrm{a}}$ values measured in the peach orchard (Photo 2) were significantly correlated with earthworm parameters, thus confirming such experimental evidences.

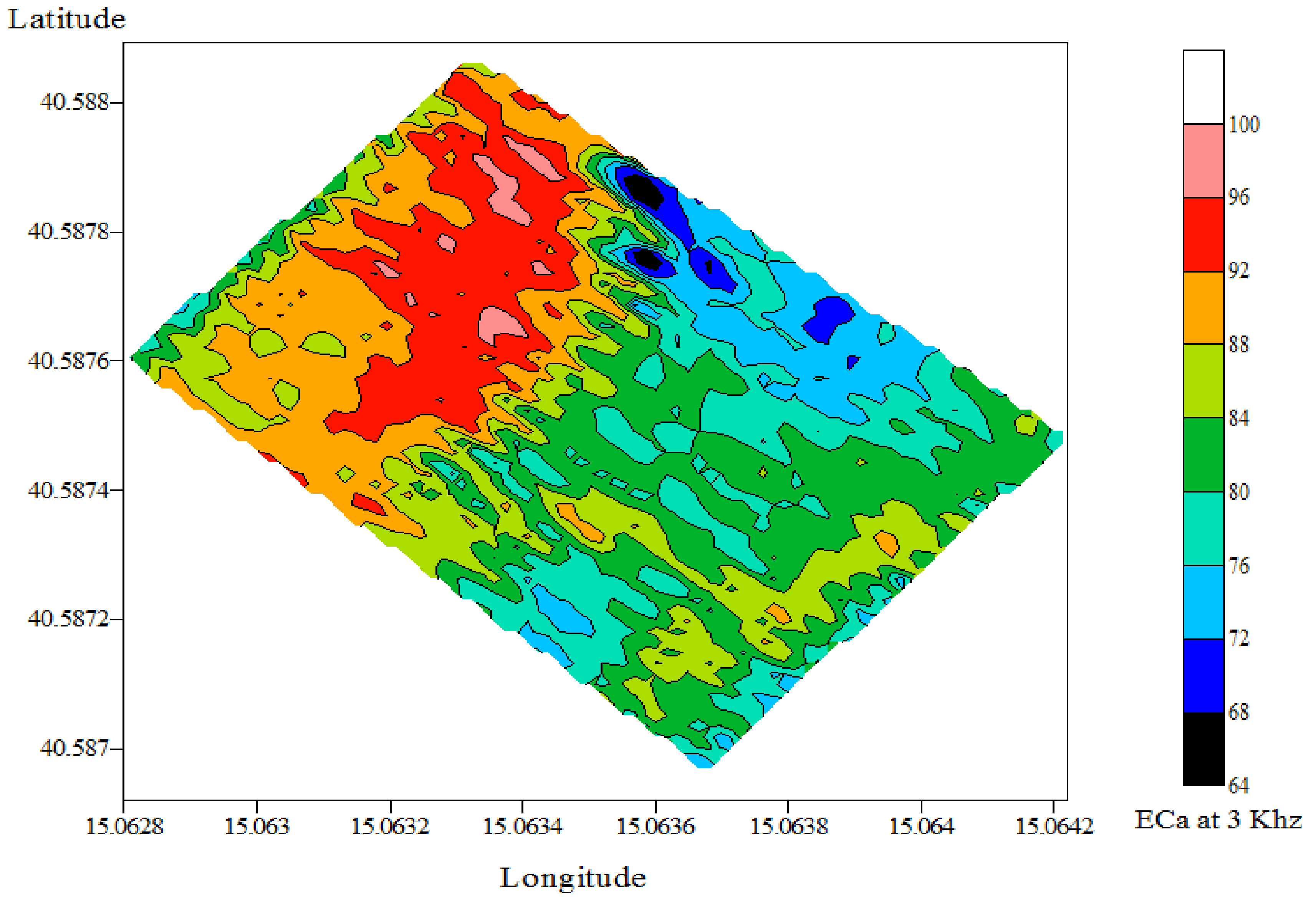

Fig. 1. EC map at $3 \mathrm{Khz}$ measured within the experimental peach orchard
The $\mathrm{EC}_{\mathrm{a}}$ signal, obtained at the different frequencies, regressed on earthworms according to a statistically significant decreasing linear model). In particular, the $3 \mathrm{kHz}$ frequency showed the strongest relations with endogeic parameters (Fig. 2).

Otherwise, the relation between the $\mathrm{EC}_{\mathrm{a}}$ and abundance values was weaker than biomass data.

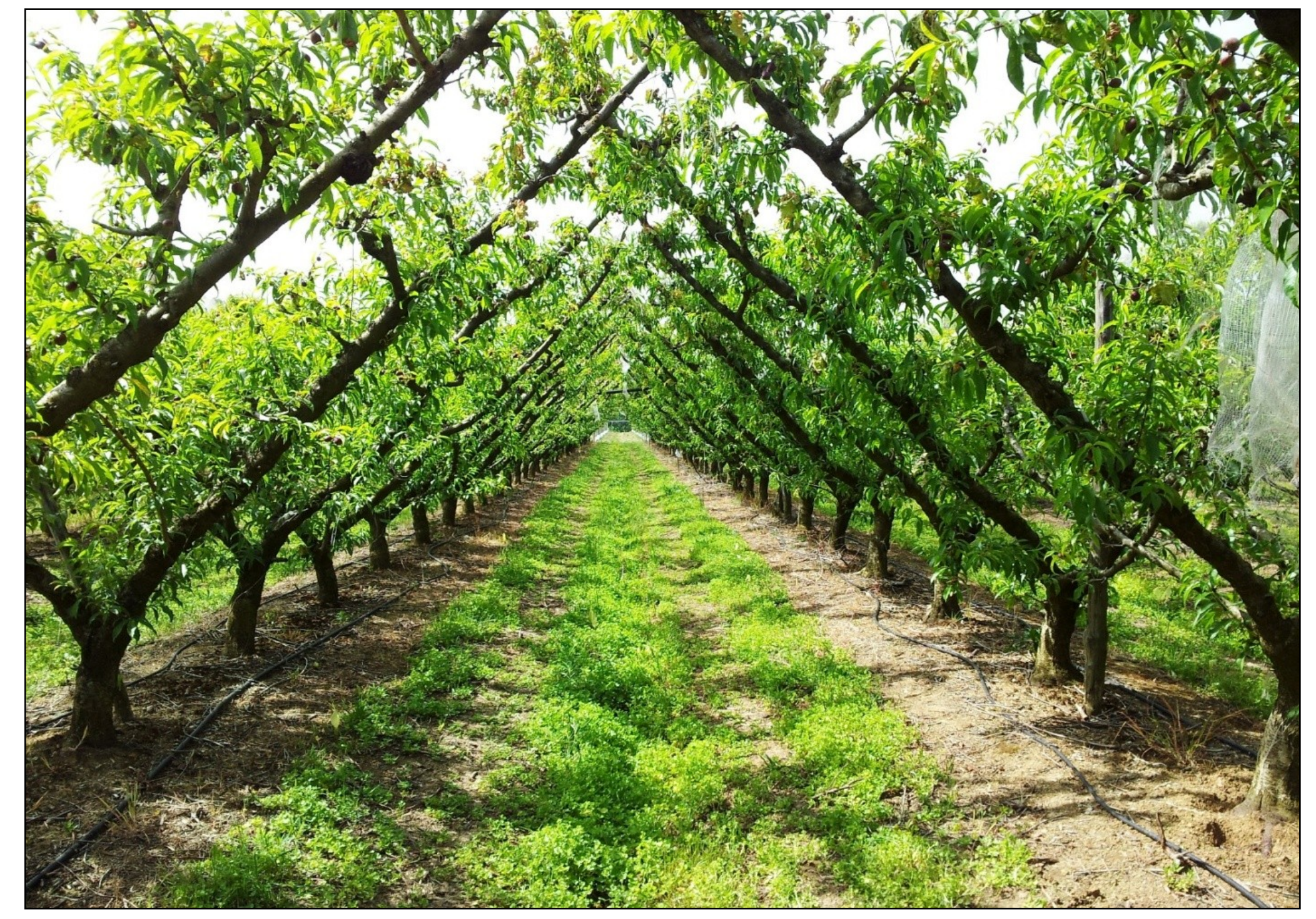

Photo 2. The experimental peach orchard
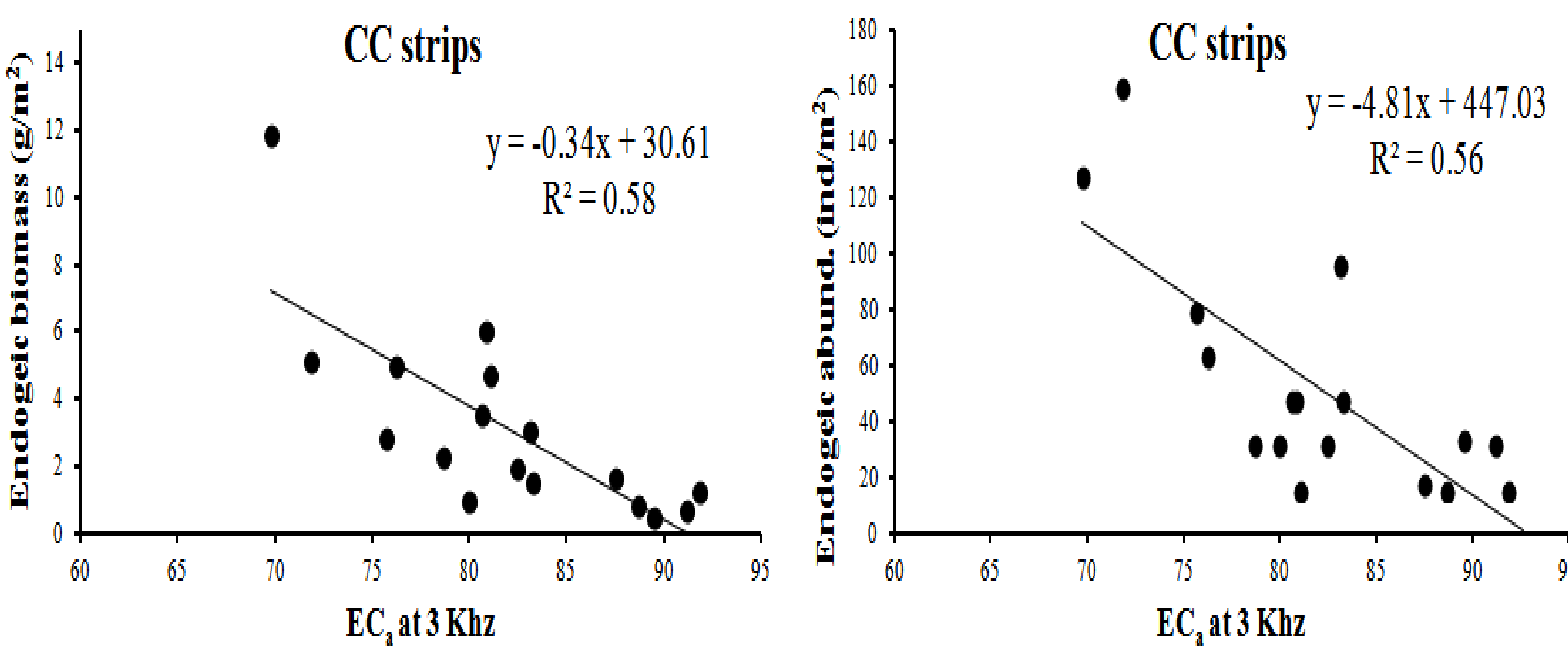

Fig. 2 Relationships between $E C$ values, abundance (ind $\left./ \mathrm{m}^{2}\right)$ and biomass $\left(g / \mathrm{m}^{2}\right)$ for endogeic earthworms.

\section{Conclusions}

The EMI technique can be a useful tool to investigate and predict the spatial and temporal variability of these biological indicators at different spatial scales.

Our findings suggest to verify the possibility of defining an integrated procedure (classical sampling methods combined with geophysical measurements) for earthworm community assessment under different pedoclimatic conditions.

According to this innovative procedure, $\mathrm{EC}_{\mathrm{a}}$ signals can identify high earthworms density areas where abundance and biomass measurements should be performed. This can reduce the expensive measurement campaigns which are usually carried out to characterize earthworm growth environments.

Moreover, it could be possible to spatialize biota data at whole field level by guaranteeing the reliability of the estimates of mean real values of earthworm parameters and their surface spatial distribution.

\section{Acknowledgements}

This research was financed by Ministero dell'Istruzione, dell'Università e della Ricerca (PRIN 2008, Carbon Cycle in managed tree ecosystems). The authors thank the farm owner Dr Giancarlo Mellone (Società Idea Natura - Eboli).

\section{References}

Coll, P., Le Cadre, E., Blanchart, E. Hinsinger, P., Villenave, C., 2011. Organic viticulture and soil quality: A longterm study in Southern France. Appl. Soil Ecol. 50: 37-44.

Joschko, M., Gebbers, R., Barkusky, D., Timmer, J., 2010. The apparent electrical conductivity as a surrogate variable for predicting earthworm abundances in tilled soils. J. Plant Nutr. Soil Sci., 173: 584-590.

Lardo E., Coll P., Palese A.M., Le Cadre E., Villenave C., Xiloyannis C., Celano G., 2012. Electromagnetic

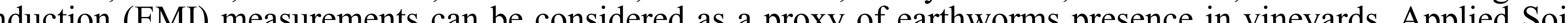
Ecology 61, 76- 84.

Pelosi, C., Bertrand, M., Capowiez, Y., Boizard, H., Roger-Estrade, J., 2009. Earthworm collection from agricultural fields: Comparisons of selected expellants in presence/absence of handsorting. Europ. J. of Soil Biol.,

Valckx, J., Cockx, L., Wauters, J., Van Meirvenne, M., Govers, G., Hernmy, M., Muys, B., 2009. Within-field spatial distribution of earthworm populations related to species interactions and soil apparent electrical 